\title{
Very early-onset inflammatory bowel disease (IBD) in infancy is a different disease entity from adult-onset IBD; one form of interleukin-10 receptor mutations
}

\author{
Jung Ok Shim and Jeong Kee Seo
}

\begin{abstract}
Infantile periods may have stronger genetic influences. Recently, studies on genetic defects in the interleukin-10 (IL-10) signaling pathway have provided new insights into inflammatory bowel disease (IBD). This study is to reveal whether mutations of IL-10 signaling pathway genes contribute to the phenotypes of IBD. Forty children who were diagnosed with IBD below the age of 10 years were enrolled. We sequenced the genes interleukin-10 receptor $A$ (IL-10RA), IL-1ORB and IL-10, and analyzed the clinical characteristics of very early-onset IBD (VEO-IBD). In total, 14 out of the 40 children developed their symptoms within 1 year of age. We found mutations in IL-1ORA in 7 out of the 40 children (17.5\%). All seven children had developed symptoms within the first year of life. Particularly, half of the children with infantile-onset IBD had IL-1ORA mutations. None of the remaining 26 children diagnosed above 1 year of age had IL-1ORA mutations. No mutations were found in IL-1ORB and IL-10. Identified IL-10RA mutations were p.(R101W), p.(Y91C), p.(R262C), p.(R117H) and p.(W69R). IL-10RA mutations were associated with onset of infancy $(P<0.001)$, perianal fistulae $(P<0.001)$, poor response to medical management $(P=0.017)$ and early surgical interventions $(P<0.001)$. VEO-IBD in infancy is phenotypically and genetically different disease entity from adult-onset or older child-onset IBD. It has a strong association with $I L-10$ receptor gene. We should consider the genotyping of genes of the IL-10 signaling pathway including IL-1ORA in patients with VEO-IBD, especially in whom with onset of perianal fistulae and severe colitis.
\end{abstract}

Journal of Human Genetics (2014) 59, 337-341; doi:10.1038/jhg.2014.32; published online 1 May 2014

Keywords: gene; inflammatory bowel disease; interleukin-10 receptor; mutation; pediatric

\section{INTRODUCTION}

Inflammatory bowel disease (IBD) may also develop in neonatal or infantile periods in less than $1 \%$ of pediatric patients. ${ }^{1,2}$ Clinical characteristics of infantile-onset, or very early-onset IBD (VEO-IBD) seem to be different from those of adult-onset or adolescent-onset IBD. Data about VEO-IBD reported severe clinical course and a high rate of resistance to immunosuppressive treatment. ${ }^{3,4}$ VEO-IBD is thought to be important to investigate the pathophysiology of IBD, because IBD that starts earlier in life may have a strong association with genetic background. The Paris classification reflected clinical practice of pediatric IBD. It just subdivided the Montreal classification A1 ( $<17$ years) into Ala, which represents 0-9 years of age, and A1b, which represents ages $10 \sim 16$ years. $^{5}$

Genome wide association studies have revealed the genetic complexity of IBD and discovered 163 candidate loci. ${ }^{6}$ However, most of them are focused to the study of common variants and may overlook the rare but loss-of-function mutations. VEO-IBD patients are very select population, and they may carry low-frequency variants. Next generation exome sequencing can overcome the limitation of genome wide association study and can identify rare disease causing variants. ${ }^{7}$ Glocker et al. ${ }^{8}$ performed genetic linkage analysis and candidate gene sequencing to identify Mendelian mutations of interleukin-10 receptor A (IL-10RA) and $I L-10 R B$ in four children with VEO-IBD. Subsequently, mutations of $I L-10 R A$ and $I L-10 R B$ have been reported. However, there are still limited data, particularly in Asians. ${ }^{9-13}$ We recently identified IL-10RA mutations in three children with 'intractable ulcerating enterocolitis in infancy' and neonatal onset Crohn's disease (CD). ${ }^{14}$

Interleukin-10 (IL-10) is an anti-inflammatory cytokine that is critical for immune homeostasis in the intestine. IL-10 signals are initiated by its binding to the IL-10 receptor, which consists of two $\alpha$ subunits of IL-10R1 (encoded by IL-10RA), and two $\beta$ subunits of IL10R2 (encoded by $I L-10 R B$ ). This complex activates the Janus kinase (Jak) 1 and tyrosine kinase (Tyk) 2, leading to phosphorylation of signal transducer and activator of transcription 3 (STAT3) and gene transcription. IL-10-mediated signaling restricts inappropriate Th17 cell expansion, which is associated with CD. ${ }^{15} I L-10$ - and $I L-10 R B-$ deficient mice develop spontaneous chronic enterocolitis. ${ }^{16}$ 
The aim of this study is to identify monogenic defects in genes involved in the IL-10 signaling pathway in children with IBD, and to investigate whether such mutations contribute to the phenotypes of IBD, especially the difference observed between VEO-IBD and IBD with the onset of older age.

\section{MATERIALS AND METHODS}

Forty Korean children diagnosed with CD or ulcerative colitis (UC) before genetic study below the age of 10 years (Paris classification Ala) at Seoul National University Children's Hospital were enrolled. Diagnosis of IBD was based on standard tools including clinical features, endoscopy with biopsies and adequate imaging of the small bowel. Thirty-seven children were diagnosed with $\mathrm{CD}$, two with $\mathrm{UC}$ and one with intractable ulcerating enterocolitis'. Follow-up periods were $2 \sim 18$ years. We subdivided groups into very early-onset IBD (Group I, defined as age of onset $<1$ year, $n=14$ ) and IBD with the age of onset 1 to $<10$ years (Group II, $n=26$ ). We obtained their clinical characteristics, including disease type, sex, age of onset, disease location, disease behavior and the presence of perianal disease, according to the Paris classification. ${ }^{5}$ Information pertaining to family history, medical treatment, surgical intervention-including the age at operation-and history of infections was also obtained.

We analyzed the peripheral blood samples from the patients for IL-10RA, $I L-10 R B$ and $I L-10$ upon informed consent. DNA was isolated using a G-DEXTM genomic DNA extraction kit (iNtRON Biotechnology, Seoul, Korea). The PCR primer pairs were used as described in Table 1. The PCR reactions were performed in a $20-\mu \mathrm{l}$ volume containing $100 \mathrm{ng}$ genomic DNA, 2.5 pmoles of each primer and AccuPower ProFi Taq PCR PreMix (Bioneer, Seoul, Korea). Initial denaturation was done at $94^{\circ} \mathrm{C}$ for $5 \mathrm{~min}, 30$ cycles of denaturation at $94^{\circ} \mathrm{C}$ for $1 \mathrm{~min}$, annealing at the temperature described in Tables 1 for $1 \mathrm{~min}$, extension at $72^{\circ} \mathrm{C}$ for $1 \mathrm{~min}$ and a final extension step at $72{ }^{\circ} \mathrm{C}$ for $10 \mathrm{~min}$. The amplified fragments were separated by $1 \%$ agarose gel electrophoresis, purified with a Qiaquick PCR purification kit (Qiagen, Hilden, Germany) and sequenced by an ABI PRISM 3730XL Analyzer (Applied Biosystems, Foster City, CA, USA). Identified variants were also sequenced in 100 healthy controls of Korean ancestry, and in silico analysis was performed using the online tools PolyPhen-2 (http://genetics.bwh.harvard.edu/pph2) ${ }^{17}$ and SIFT (http://sift.bii.a-star.edu.sg/www/SIFT_seq_submit2.html). ${ }^{18}$

Statistical analysis for the phenotypic correlation was performed by MantelHaenszel $\chi^{2}$ test, one-way analysis of variance and Kaplan-Meier test using SPSS version 20.0 (IBM, New York, NY, USA).
This study was approved by the Institutional Review Boards at Seoul National University Hospital (Seoul, Korea).

\section{RESULTS}

Genotypes of IL-10RA, IL-10RB and IL-10

We found mutations in IL-10RA in 7 out of 14 children in Group I. None of 26 children in Group II had mutations in IL-10RA. No mutations of $I L-10 R B$ and $I L-10$ were detected in all 40 children. Overall detection rate of $I L-10 R A$ mutations was $17.5 \%$ (7/40) in total patients. Particularly, the rate was $50.0 \%(7 / 14)$ in Group I.

Identified IL-10RA mutations were p.(R101W), p.(Y91C), p.(R262C), p.(R117H) and p.(W69R). The most common mutations were c. $(301 \mathrm{C}>\mathrm{T}), \mathrm{p} .(\mathrm{R} 101 \mathrm{~W})$ and c. $(272 \mathrm{~A}>\mathrm{G})$, p. $(\mathrm{Y} 91 \mathrm{C})$ in exon 3 in four children. p.(R262C) and p.(R117H) were found in two children, respectively, and p.(W69R) and p.(A10G) were also found. All children have compound heterozygous mutations, but one child has only one mutation.

Of them, c. $(272 \mathrm{~A}>\mathrm{G}), \mathrm{p} .(\mathrm{Y} 91 \mathrm{C})$ and c. $(205 \mathrm{~T}>\mathrm{C})$, p. (W69R) were novel variants. We investigated 100 healthy controls of Korean ancestry and they were not found. The PolyPhen-2 predicted that p.(Y91C) and p.(W69R) would probably be damaging with scores of 1.000. The SIFT tool predicted that p.(W69R) might affect protein function with a score of 0.00 and p.(Y91C) might be tolerated with a score of 0.12 .

Normal polymorphisms were also found. c.(1051A $>$ G), p.(R351G) and c. $(670 \mathrm{~A}>\mathrm{G})$, p.(I224V) in $I L-10 R A$, and c.(139 A $>$ G), p.(K47E) in $I L-10 R B$ which were identified in 40,20 and 31 children, respectively.

\section{Phenotypic characteristics of $I L$-10RA-deficient children}

Of total seven children with IL-10RA mutations, six children developed their symptoms within 1 month after birth, and one child at 6 months (median 10 days after birth). Colonoscopies with histologic examinations were consistent with $\mathrm{CD}$ in six of seven children. One child was diagnosed with 'intractable ulcerating enterocolitis in infancy' 15 years ago, which was first described by Sanderson et al., ${ }^{19}$ and we recently found IL-10RA mutations in her blood sample and reported it. ${ }^{14}$ All seven children (100\%) had

Table 1 Primer sequences for candidate genes

\begin{tabular}{|c|c|c|c|c|}
\hline Gene & Exon & Forward primer & Reverse primer & ${ }^{\circ} \mathrm{C}^{\mathrm{a}}$ \\
\hline \multirow[t]{7}{*}{ IL-1ORA } & 1 & 5'-CGCTAGCGCCCCAGGACAG-3' & 5'-GTTTGCGGGTTGGGGGTTTG-3' & 64 \\
\hline & 2 & 5'-ATGTGCCCACTCTGCCCCTTACG-3' & 5'-GGGCCCTCAGGCACTCACTTCATT-3' & 61 \\
\hline & 3 & 5'-GGGCTGTCCCAGTTTCTCCCAATG-3' & 5'-CCCAACCCACCCCAAGACCTCTC-3' & 61 \\
\hline & 4 & 5'-CAAAGTCTCGGCGGGGACACC-3' & 5'-ССTCCTCTGCCCACCCACCAT-3' & 61 \\
\hline & 5 & 5'-AGGCCCACCAGCTCTCAGTGTCC-3' & 5'-CCAGGTGCACGCGTTTTGGATT-3' & 60 \\
\hline & 6 & 5'-CTTGGGCCACTCACTGAATGGTT-3' & 5'-CCCACAGCGCTTGATGAAGGTAT-3' & 60 \\
\hline & 7 & 5'-CCTTCCCCGGCAGCACTGG-3' & 5'-GCAGAGGAGCAGGCATGGCTAAAA-3' & 63 \\
\hline \multirow[t]{7}{*}{ IL-1ORB } & 1 & 5'-GCGCCTTTCAAAGCTTGCGAGGAT-3' & 5'-GGCCGTGGCGTTTGCATCTTCTCT-3' & 65 \\
\hline & 2 & 5'-ACCCACGTGGCCTTTGAAGACAT-3' & 5'-GTGGCCACGAGAATTTCCCAGAC-3' & 60 \\
\hline & 3 & 5'-CCAGTCAGCCTCAGGGAGAC-3' & 5'-GGGCCCCAACATAGTCACAT-3' & 54 \\
\hline & 4 & 5'-ACTTCCGTGGACTAATTGTTCTGC-3' & 5'-CTTCAGGGAGGGAAAGGTCTG-3' & 55 \\
\hline & 5 & 5'-AGTCCCCCAAAGTGCTGTGATTAC-3' & 5'-GGGCGATAGATTTCTGAACTGAGC-3' & 57 \\
\hline & 6 & 5'-TCTGAGACGTCCCCCAAGATAAAC-3' & 5'-TGGGCAGCCCTAACTAGAAAGGAA-3' & 57 \\
\hline & 7 & 5'-CCAGCCAGGAGTTCTGTGAAAA-3' & 5'-TAGATGTGGGGCTGGCTCAGAT-3' & 57 \\
\hline \multirow[t]{4}{*}{ IL-10 } & 1 & 5'-GTGCCGGGAAACCTTGATTGTGG-3' & 5'-GGGGGAATAGGTGTTGGGGATGG-3' & 60 \\
\hline & $2 / 3$ & 5'-GGGCATCAAAAAGACCGCATTTCA-3' & 5'-CCCCCAACGCCTGCTCAAAGA-3' & 60 \\
\hline & 4 & 5'-CCACCAGCTTGTCCCCTAAGTGTG-3' & 5'-TGGCCGGCCAGCCTAACC-3' & 59 \\
\hline & 5 & 5'-AGCATGAGGGAGGGGAGCCTATTT-3' & 5'-GCGCCCGGCCTAGAACCAA-3' & 57 \\
\hline
\end{tabular}

annealing temperature. 
Table 2 Genotypic and phenotypic characteristics of children with very early-onset inflammatory bowel disease

\begin{tabular}{|c|c|c|c|c|c|c|c|c|}
\hline No. & $\begin{array}{l}\text { Clinical } \\
\text { diagnosis }\end{array}$ & $\begin{array}{l}\text { Age of } \\
\text { onset }\end{array}$ & Sex & IL-1ORA mutations & Location & $\begin{array}{l}\text { Perianal } \\
\text { disease }\end{array}$ & Surgery (age) & $\begin{array}{c}\text { Follow-up } \\
\text { (years) }\end{array}$ \\
\hline 1 & $\begin{array}{l}\text { Crohn's } \\
\text { Disease }\end{array}$ & 0 day & Male & $\begin{array}{l}c .350 G>A(p . R 117 H) \\
c .272 A>G(p . Y 91 c)^{b}\end{array}$ & L2 & $\begin{array}{l}\text { Abscess, } \\
\text { fistulae }\end{array}$ & - & 5 \\
\hline $2^{\mathrm{a}}$ & $\begin{array}{l}\text { Crohn's } \\
\text { Disease }\end{array}$ & 3 days & Female & $\begin{array}{l}\text { c.301C }>\text { T (p.R101W) } \\
\text { c. } 272 A>G(p . Y 91 C)^{b}\end{array}$ & L3 & Fistulae & $\begin{array}{l}\text { Fistulectomy and ileostomy ( } 10 \text { months) ileal resection } \\
\text { and ileoileal anastomosis ( } 5 \text { years) }\end{array}$ & 5 \\
\hline 3 & $\begin{array}{l}\text { Crohn's } \\
\text { Disease }\end{array}$ & 10 days & Female & c. $272 A>G(p . Y 91 C)^{b}$ & L3 & $\begin{array}{l}\text { Rectovaginal } \\
\text { fistulae }\end{array}$ & $\begin{array}{l}\text { Colostomy ( } 3 \text { months), subtotal colectomy ( } 8 \text { months), } \\
\text { fistulectomy ( } 16 \text { months), ileostomy ( } 21 \text { months) }\end{array}$ & 9 \\
\hline 5 & $\begin{array}{l}\text { Crohn's } \\
\text { Disease }\end{array}$ & 1 month & Female & $\begin{array}{l}\text { c.301C }>T(p . R 101 W) \\
\text { c. } 205 T>C(p . W 69 R)^{b}\end{array}$ & L2 & $\begin{array}{l}\text { Anovestibular } \\
\text { fistulae }\end{array}$ & $\begin{array}{l}\text { Sigmoid colostomy ( } 2 \text { months), fistulectomy and } \\
\text { anoplasty ( } 2 \text { months), ileostomy ( } 5 \text { months) }\end{array}$ & 2 \\
\hline 6 & $\begin{array}{l}\text { Crohn's } \\
\text { Disease }\end{array}$ & 6 months & Female & $\begin{array}{l}\text { c.301C }>\text { T (p.R101W) } \\
\text { c.784C }>\text { T (p.R262C) }\end{array}$ & L2 & $\begin{array}{l}\text { Rectovaginal } \\
\text { fistulae }\end{array}$ & $\begin{array}{l}\text { Fistulectomy and vaginoplasty ( } 2 \text { years), } \\
\text { colectomy ( } 2 \text { years) }\end{array}$ & 18 \\
\hline 8 & $\begin{array}{l}\text { Crohn's } \\
\text { Disease }\end{array}$ & 14 days & Male & Wild type & L2L4a & - & Proctocolectomy and ileostomy (15 years) & 17 \\
\hline 9 & $\begin{array}{l}\text { Crohn's } \\
\text { Disease }\end{array}$ & 22 days & Male & Wild type & L2 & - & Hemicolectomy (11 years) & 16 \\
\hline 10 & $\begin{array}{l}\text { Crohn's } \\
\text { Disease }\end{array}$ & 2 months & Female & Wild type & L3 & - & Hemicolectomy (11 years) & 11 \\
\hline 11 & $\begin{array}{l}\text { Crohn's } \\
\text { Disease }\end{array}$ & 1 month & Female & Wild type & L3L4b & - & - & 18 \\
\hline 12 & $\begin{array}{l}\text { Crohn's } \\
\text { Disease }\end{array}$ & 3 months & Male & Wild type & L3 & Fistulae & - & 4 \\
\hline 13 & $\begin{array}{l}\text { Crohn's } \\
\text { Disease }\end{array}$ & 6 months & Male & Wild type & L2 & Fistulae & - & 2 \\
\hline
\end{tabular}

apatients have been reported previously by Shim et al. ${ }^{14}$

bNovel mutations. Allele frequencies were 0 of 200 healthy control alleles. The PolyPhen-2 predicted that p.(Y91C) and p.(W69R) would probably be damaging with scores of 1.000 . The SIFT predicted that $p$.(W69R) might affect protein function with a score of 0.00 and p.(Y91C) might be tolerated with a score of 0.12 .

perianal diseases including rectovaginal or perianal fistulae. Three had frequent oral ulcers. All were treated with immunosuppressants with corticosteroid, azathioprine and/or infliximab. All children except one $(85.7 \%)$ underwent surgery because of the poor response to medical management including immunosuppressive therapy. Five children $(71.4 \%)$ underwent bowel resections (age range 8 months $\sim 5$ years, at the time of first operation), and five children (71.4\%) underwent ileostomy or colostomy (age range 3 months $\sim 2$ years). Five children underwent multiple surgical interventions.

Three had recurrent skin folliculitis, and three had recurrent infections such as pneumonia, otitis media, varicella infection, candidial fungemia or sepsis. One patient who has been followed up as 'intractable ulcerating enterocolitis in infancy' has a family history of 'ulcerating enterocolitis in infancy', whose two brothers ${ }^{20}$ died of severe colitis and sepsis during neonatal periods. All but one patient had no family histories. None had parental consanguinity. Characteristic of children with VEO-IBD with or without mutations were summarized in Table 2.

The $I L-10 R A$ mutations were associated with younger age of onset ( $<1$ year) $(P<0.001)$, perianal fistulae $(P<0.001)$, surgical interventions due to poor response to medical managements $(P=0.017)$ and early surgical interventions $(P<0.001)$. Comparisons of phenotypes
Table 3 Comparisons between Group I and Group II

\begin{tabular}{lccc}
\hline & $\begin{array}{c}\text { Group I } \\
(\mathrm{n}=14)\end{array}$ & $\begin{array}{c}\text { Group II } \\
(\mathrm{n}=26)\end{array}$ & P-value \\
\hline Age of onset & $59.9 \pm 70.2$ days & $6.83 \pm 2.73$ years & \\
Patients with IL-10RA & $7(50 \%)$ & $0(0 \%)$ & $<0.001$ \\
mutations, $n$ & $9(64.3 \%)$ & $6(23.1 \%)$ & 0.017 \\
Perianal disease, $n$ & $9(64.3 \%)$ & $3(11.5 \%)$ & 0.001 \\
Surgical treatments, $n$ & $5.98 \pm 5.55$ years & $15.3 \pm 1.15$ years & 0.001 \\
Age at first operation & L2 9 & L2 3 & $0.021^{\text {a }}$ \\
Disease location, $n$ & L3 3 & L3 15 & \\
& L4b 2 & L1 4 & \\
& & L4a 6 & \\
& & L4b 1 &
\end{tabular}

aStatistical differences of the proportion of L2 and L3.

between Group I and Group II, and between IL-10RA mutations group and without mutations group were summarized in Tables 3, 4 and Figure 1. 
Table 4 Comparison between children with IL-10RA mutations and children without mutations

\begin{tabular}{|c|c|c|c|}
\hline & $\begin{array}{l}\text { Inflammatory bowel disease with } \\
\text { IL-1ORA mutations }(\mathrm{n}=7)\end{array}$ & $\begin{array}{l}\text { Inflammatory bowel disease without } \\
\qquad \text { mutations }(\mathrm{n}=33)\end{array}$ & P-value \\
\hline Age of onset & $36.1 \pm 64.8$ days & $5.34 \pm 3.69$ years & $<0.001$ \\
\hline Perianal disease, $n$ & 7 (100\%) & $8(24.2 \%)$ & $<0.001$ \\
\hline Surgical treatments, $n$ & $6(85.7 \%)$ & $6(18.2 \%)$ & 0.017 \\
\hline Age of first operation & $1.83 \pm 1.71$ years & $13.0 \pm 2.28$ years & $<0.001$ \\
\hline Disease location, $n$ & L2 5 & L2 7 & $0.151^{\circ}$ \\
\hline \multirow[t]{3}{*}{ (Crohn's disease) } & L3 2 & L3 18 & \\
\hline & L4b 1 & L1 4 & \\
\hline & & L4b 7 & \\
\hline
\end{tabular}

a Statistical differences of the proportion of L2 and L3.

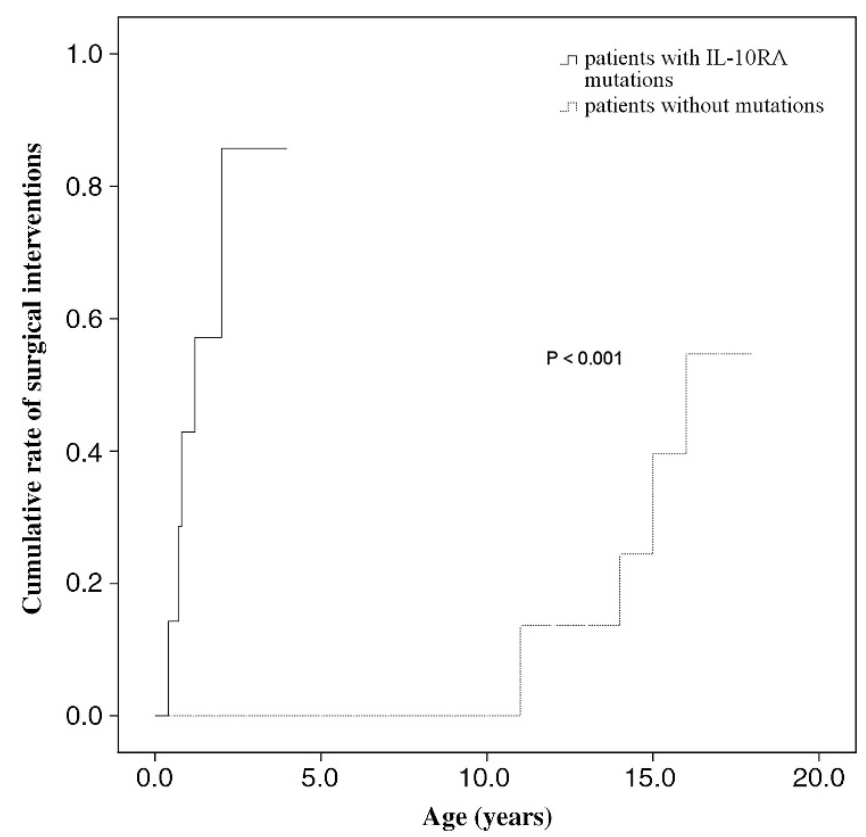

Figure 1 Cumulative rate of surgical interventions in children with inflammatory bowel disease by age. Children with interleukin-10 receptor $A$ (IL-1ORA) mutations underwent early surgical interventions because of poor response to medical treatments than children wihtout a mutation in genes of the IL-10 signaling pathway (Kaplan-Meier curve, $P<0.001$ ).

\section{DISCUSSIONS}

Glocker et al. ${ }^{8}$ first indicated that IBD may be a monogenic disorder. Homozygous mutations of p.(W159X) in $I L-10 R B$ were found in Kurdish siblings with consanguineous parents, homozygous IL10-RA mutations of p.(G141R) in an Arabic child and p.(T84I) homozygous mutations in a Caucasian infant. Children in that report exhibited symptoms within the first year of life with severe colitis and perianal diseases. They also found $I L-10$ mutations in two infants. ${ }^{21}$ Kotlarz et $a l .{ }^{9}$ reported $I L-10 R A$ mutations in three children with IBD, $I L-10 R B$ mutations in six children and $I L-10$ mutations in three children. Begue et al. ${ }^{13}$ investigated 13 children and reported one child with IL-10RA mutations and one child with IL-10RB mutations. Moran et al. ${ }^{10}$ studied 188 children with IBD and found mutations in IL-10RA in one child. More recently, Engelhardt et al. ${ }^{12}$ reported mutations in IL-10RA or IL-10RB in seven children with IBD. There are not enough data and most were limited to Whites, Turkish and Arab. Many of them, particularly children in Arab, had histories of parental consanguinity.
In this study, we identified mutations of IL-10RA in seven Korean children with VEO-IBD. Particularly, 50\% of our children with VEO-IBD (onset within the first year of life) had IL-10RA mutations. This is the highest detection rate ever reported. No children had parental consanguinity. There might be ethnical differences compared with White who showed low detection rate. The onset of symptoms post the first year of life did not correlated with IL-10-related mutations. All children with IL-10RA mutations developed their symptoms along with severe colitis and perianal fistulae (behavior ' $\mathrm{p}$ ' in Paris classification) during the infantile period. Poor response to immunosuppressive therapy in all patients except one (85.7\%) resulted in multiple surgical interventions early in life. With respect to the one exception, the child, currently 5 years old, had a relatively short follow-up period. He also responded poorly to other medications, and has been treated with infliximab. One child with an IL-10RA mutation in one allele showed very similar phenotypes to other children with compound heterozygote mutations. She developed symptoms 10 days after birth with a rectovaginal fistula and underwent multiple surgeries in infancy. It is possible she also has a mutation in the other allele, which, however, failed to be detected by direct sequencing methods. Children who did not have a mutation required fewer surgical interventions, and underwent surgery only after 10 years of age. The IL-10RA mutations demonstrated a significant association with the onset of symptoms in infancy, the presence of perianal fistulae and the requirement of early surgical interventions. To our knowledge, present study is the first report of phenotype analysis. Our investigation identified distinct phenotypic characteristics in IL-10RA-deficient patients compared with children without mutations.

The Paris classification ${ }^{5}$ determined an age cut-off point of 10 years in pediatric IBD. The classification focused on the location or extent of disease, ${ }^{22}$ and the variation in serologic responses ${ }^{23}$ in CD. VEOIBD represents a rare phenotype within the pediatric IBD. According to the EUROKIDS registry of pediatric IBD patients, only 21 of 2022 pediatric patients manifested their symptoms during infancy. ${ }^{24}$ Cannioto et al. $^{4}$ reported severe disease courses in VEO-IBD including resistance to immunosuppressive treatment and colectomy. These findings can be explained by the high rate of IL-10RA mutations in children with VEO-IBD in our study. The differences of clinical characteristics in Group I and Group II were consistent with the differences between IL-10RA mutations group and without mutations group. In previous studies, the presence of perianal disease and disease behavior do not differ with respect to age of onset. ${ }^{25,26}$ However, in our study, children with VEO-IBD with IL-10RA mutations were more likely to have perianal disease than IBD without an IL-10RA mutation. Our investigation supports the 
evidence to subdivide a separate group of children with IBD at a very early-onset $(0 \sim 1$ year $)$ in the Paris classification.

Most of our patients with IL-10RA mutations were clinically and endoscopically diagnosed with $\mathrm{CD}$, and one patient with 'intractable ulcerating enterocolitis in infancy' shared same mutations in patients with CD. Another study reported that the IL-10RA polymorphisms were associated with early-onset UC. ${ }^{10}$ These findings indicate that it may be more important to identify $I L-10 R$ mutations than to classify the disease types (CD or UC) in VEO-IBD.

Three out of our seven children with IL-10RA mutations had histories of folliculitis and recurrent infections such as sepsis, pneumonia and otitis media. The immunologic status of one patient was evaluated before treatment, and results revealed a relatively low CD3 T lymphocyte level. ${ }^{14}$ Recently, Engelhardt et al. ${ }^{12}$ reported certain subtle and variable immunological abnormalities in patients with $I L-10 R$ mutations. These findings demonstrate an association between the altered IL-10 signaling pathway and immune defects. The occurrence of an IBD phenotype in Wiskott-Aldrich syndrome, Immunodysregulation, polyendocrinopathy, enteropathy, X-linked syndrome (IPEX) and, in particular, chronic granulomatous disease have been reported and it indicates that IBD may be the complex immunodeficiency disorder. ${ }^{27}$

Very early-onset IBD in infancy is phenotypically and genetically different from IBD with onset of older age. It has a strong association with $I L-10$ receptor gene. It might be needed to subdivide a group of children with very early-onset IBD $(0 \sim 1$ year $)$ in the Paris classification. We should consider genotyping for genes of the IL-10 signaling pathway including IL-10RA in patients with VEO-IBD in infancy, particularly in cases that are associated with an onset of perianal fistulae and severe colitis.

\section{CONFLICT OF INTEREST}

The authors declare no conflict of interest.

1 Seo, J. K. Pediatric inflammatory bowel disease (IBD): phenotypic, genetic and therapeutic differences between early-onset and adult-onset IBD. Korean J. Ped. Gastroenterol. Nutr. 14, 1-25 (2011).

2 Seo, J. K., Yeon, K. M. \& Chi, J. G. Inflammatory bowel disease in children. J. Korean Med. Sci. 7, 221-235 (1992).

3 Ruemmele, F. M., El Khoury, M. G., Talbotec, C., Maurage, C., Mougenot, J. F. \& Schmitz, J. Characteristics of inflammatory bowel disease with onset during the first year of life. J. Pediatr. Gastroenterol. Nutr. 43, 603-609 (2006).

4 Cannioto, Z., Berti, I., Martelossi, S., Bruno, I., Giurici, N. \& Crovella, S. IBD and IBD mimicking enterocolitis in children younger than 2 years of age. Eur. J. Pediatr. 168, 149-155 (2009).

5 Levine, A., Griffiths, A., Markowitz, J., Wilson, D. C., Turner, D. \& Russell, R. K. Pediatric modification of the Montreal classification for inflammatory bowel disease: the Paris classification. Inflamm. Bowel Dis. 17, 1314-1321 (2011).
6 Uhlig, H. H. Monogenic diseases associated with intestinal inflammation: implications for the understanding of inflammatory bowel disease. Gut. 62, 1795-1805 (2013).

7 Christodoulou, K., Wiskin, A. E., Gibson, J., Tapper, W., Willis, C. \& Afzal, N. A. Next generation exome sequencing of paediatric inflammatory bowel disease patients identifies rare and novel variants in candidate genes. Gut. 62, 977-984 (2012).

8 Glocker, E. O., Kotlarz, D., Boztug, K., Gertz, E. M., Schaffer, A. A. \& Noyan, F. Inflammatory bowel disease and mutations affecting the interleukin-10 receptor. N. Engl. J. Med. 361, 2033-2045 (2009).

9 Kotlarz, D., Beier, R., Murugan, D., Diestelhorst, J., Jensen, O. \& Boztug, K. Loss of interleukin-10 signaling and infantile inflammatory bowel disease: implications for diagnosis and therapy. Gastroenterology 143, 347-355 (2012).

10 Moran, C. J., Walters, T. D., Guo, C. H., Kugathasan, S., Klein, C. \& Turner, D. IL-10R polymorphisms are associated with very-early-onset ulcerative colitis. Inflamm. Bowel Dis. 19, 115-123 (2013).

11 Mao, H., Yang, W., Lee, P. P., Ho, M. H., Yang, J. \& Zeng, S. Exome sequencing identifies novel compound heterozygous mutations of IL-10 receptor 1 in neonatalonset Crohn's disease. Genes Immun. 13, 437-442 (2012).

12 Engelhardt, K. R., Shah, N., Faizura-Yeop, I., Kocacik Uygun, D. F., Frede, N. \& Muise, A. M. Clinical outcome in IL-10- and IL-10 receptor-deficient patients with or without hematopoietic stem cell transplantation. J. Allergy Clin. Immunol. 131, 825-830 (2013).

13 Begue, B., Verdier, J., Rieux-Laucat, F., Goulet, O., Morali, A. \& Canioni, D. Defective IL10 signaling defining a subgroup of patients with inflammatory bowel disease. Am. J. Gastroenterol. 106, 1544-1555 (2011).

14 Shim, J. O., Hwang, S., Yang, H. R., Moon, J. S., Chang, J. Y. \& Ko, J. S. Interleukin-10 receptor mutations in children with neonatal-onset Crohn's disease and intractable ulcerating enterocolitis. Eur. J. Gastroenterol. Hepatol. 25, 1235-1240 (2013).

15 Paul, G., Khare, V. \& Gasche, C. Inflamed gut mucosa: downstream of interleukin-10. Eur. J. Clin. Invest. 42, 95-109 (2012).

16 Kuhn, R., Lohler, J., Rennick, D., Rajewsky, K. \& Muller, W. Interleukin-10-deficient mice develop chronic enterocolitis. Cell 75, 263-274 (1993).

17 Adzhubei, I. A., Schmidt, S., Peshkin, L., Ramensky, V. E., Gerasimova, A. \& Bork, P. A method and server for predicting damaging missense mutations. Nat. Methods 7, 248-249 (2010).

18 Doerks, T., Copley, R. R., Schultz, J., Ponting, C. P. \& Bork, P. Systematic identification of novel protein domain families associated with nuclear functions. Genome Res. 12, 47-56 (2002).

19 Sanderson, I. R., Risdon, R. A. \& Walker-Smith, J. A. Intractable ulcerating enterocolitis of infancy. Arch. Dis. Child. 65, 295-299 (1990).

20 Jeong, J. Y., Seo, J. K., Park, K. W. \& Chi, J. G. A case of 'intractable ulcerating enterocolitis' of infant. Korean J. Pediatr. 38, 264-270 (1995).

21 Glocker, E. O., Frede, N., Perro, M., Sebire, N., Elawad, M. \& Shah, N. Infant colitis-it's in the genes. Lancet 376, 1272 (2010).

22 Meinzer, U., Idestrom, M., Alberti, C., Peuchmaur, M., Belarbi, N. \& Bellaiche, M. Ileal involvement is age dependent in pediatric Crohn's disease. Inflamm. Bowel Dis. 11, 639-644 (2005).

23 Markowitz, J., Kugathasan, S., Dubinsky, M., Mei, L., Crandall, W. \& LeLeiko, N. Age of diagnosis influences serologic responses in children with Crohn's disease: a possible clue to etiology? Inflamm. Bowel Dis. 15, 714-719 (2009).

24 de Bie, C. I., Buderus, S., Sandhu, B. K., de Ridder, L., Paerregaard, A. \& Veres, G. Diagnostic workup of paediatric patients with inflammatory bowel disease in Europe: results of a 5-year audit of the EUROKIDS registry. J. Pediatr. Gastroenterol. Nutr. 54, 374-380 (2012).

25 Shaoul, R. Karban, A., Reif, S., Weiss, B., Shamir, R. \& Tamir, A. Disease behavior in children with Crohn's disease: the effect of disease duration, ethnicity, genotype, and phenotype. Dig. Dis. Sci. 54, 142-150 (2009).

26 Tarrant, K. M., Barclay, M. L., Frampton, C. M. \& Gearry, R. B. Perianal disease predicts changes in Crohn's disease phenotype-results of a population-based study of inflammatory bowel disease phenotype. Am. J. Gastroenterol. 103, 3082-3093 (2008).

27 Glocker, E. \& Grimbacher, B. Inflammatory bowel disease: is it a primary immunodeficiency? Cell. Mol. Life Sci. 69, 41-48 (2012). 